\title{
Biologia reprodutiva de Aegla castro Schmitt (Crustacea, Anomura, Aeglidae) no Buraco do Padre, Ponta Grossa, Paraná, Brasil ${ }^{1}$
}

\author{
Bianca de Paula Swiech-Ayoub ${ }^{2,3}$ \\ Setuko Masunari ${ }^{2}$
}

\begin{abstract}
Reproductive biology of Aegla castro Schmitt (Crustacea, Anomura, Aeglidae) from Buraco do Padre, Quebra-Perna River, Ponta Grossa, Paraná State, Brazil. The reproductive biology of Aegla castro Schmitt, 1942 from Buraco do Padre, Ponta Grossa, Paraná State, was analyzed. The sampling was done monthly, from February/97 to January $/ 98$ with aid of hand net and screens at three stations, under an effort of 120 minutes. The mean air temperature ranged from $15.0^{\circ} \mathrm{C}$ (May, July, September and October) to $24.3^{\circ} \mathrm{C}$ (December and January), and the water temperature from $15.8^{\circ} \mathrm{C}$ (July) to $22.3^{\circ} \mathrm{C}$ (December). The dissolved oxygen oscillated from $95.7 \%$ (March) to $100.2 \%$ saturation (August) and the $\mathrm{pH}$ from 6.1 (July) to 7.2 (September). A total of 827 specimens were obtained among which 384 males, 311 females and 132 juveniles. Males predominated over females, but the sex ratio followed the standard model of 1:1. Juveniles were found during all the study period, except in May and September. The peaks of their frequency curve occurred in April and December. The reproduction is discontinuous type with greater intensity in the colder months, from May to October. The females take part of the reproduction for two consecutive years and the species longevity was estimated in two years. The carapace length of the various development stages ranged as following: juveniles $\leq 6.4 \mathrm{~mm}$, immature females and males $=$ from 6.5 to $12.2 \mathrm{~mm}$ and mature females and males $=$ from 12.3 to $29.5 \mathrm{~mm}$.
\end{abstract}

KEY WORDS. Aegla castro, reproduction, recruitment, Ponta Grossa, Paraná State

Os estudos que abordam aspectos populacionais dos aeglídeos são raros: do estrangeiro citam-se apenas os trabalhos de MOUCHET (1932) e de BAHAMONDE \& LÓPEZ (1961). O primeiro tratou de aspectos relativos ao ciclo de vida como as variações na proporção entre os sexos com as estações do ano, e o último sobre a biologia de Aegla laevis laevis (Latreille, 1818), antigamente conhecido como Galathea laevis, em El Monte no Chile.

No Brasil, destacam-se as pesquisas de LÓPEZ (1965) e de RODRIGUES \& HeBLING (1978), que trataram de aspectos populacionais, respectivamente, de $A$. paulensis Schmitt, 1942, nos arroios e reservatórios dos arredores de Paranapiacaba, no Alto da Serra e de $A$. perobae Hebling \& Rodrigues, 1977 da Gruta da Peroba, na Serra de São Pedro, ambas as localidades no Estado de São Paulo.

1) Contribuição número 1226 do Departamento de Zoologia, Universidade Federal do Paraná.

2) Departamento de Zoologia, Universidade Federal do Paraná. Caixa Postal 19020, 81531-990 Curitiba, Paraná, Brasil. E-mail: setmas@bio.ufpr.br

3) Curso de Pós-graduação em Ciências Biológicas, Zoologia. Departamento de Zoologia, Universidade Federal do Paraná. Caixa Postal 19020, 81531-990 Curitiba, Paraná, Brasil. Bolsista da CAPES. 
Mais recentemente, BUENO \& BOND-BUCKUP (2000) descreveram a dinâmica populacional de A. platensis Schmitt, 1942 no Arroio do Mineiro, município de Taquara, Rio Grande do Sul. Esta espécie se reproduz o ano inteiro, com número maior de fêmeas ovígeras em julho; o tamanho da primeira maturação foi estimado entre 14,40 e 15,60 de comprimento do cefalotórax e a proporção de sexos foi de 1:1. Para a mesma população, BUENo et al. (2000) estabeleceram a curva de crescimento de von Bertalanffy para machos e fềmeas.

Os dados sobre a biologia das espécies acima citadas de Aegla demonstram que a biologia reprodutiva é peculiar para cada espécie, no que concerne à época de desova e de recrutamento de juvenis.

A atividade reprodutiva de uma espécie é uma das expressões fenotípicas mais conspícuas da flutuação de densidade. $\mathrm{O}$ incremento do número de juvenis promovido pela reprodução deve equilibrar o tamanho de uma população persistente, em contraposição à mortalidade e à emigração (SASTRY 1983).

JARA et al. (1995), num estudo de atualização dos limites de distribuição geográfica de A. papudo Schmitt, 1942 no Chile, registraram a preocupação com a degradação dos hábitats destes animais associada às perturbações induzidas por antropia, e conseqüente redução do tamanho das populações desta espécie.

Como a literatura não contempla qualquer informação sobre aspectos ecológicos de $A$. castro Schmitt, 1942, o presente trabalho tem por objetivo estudar a biologia reprodutiva da espécie no Buraco do Padre e imediações, descrevendo a proporção de sexos, período reprodutivo, recrutamento de juvenis e estádios de desenvolvimento. Este estudo deverá ampliar o conhecimento acerca da espécie que mostra fragilidade frente à crescente ocupação do homem, tanto no processo de urbanização como na prática da agricultura. Informações sobre a dinâmica da população destes animais, certamente, trarão significativos subsidios para eventuais recuperações de ecossistemas de águas continentais.

\section{MATERIAL E MÉTODOS}

Doze coletas foram realizadas mensalmente de fevereiro/1997 a janeiro/1998, no Buraco do Padre, localizado no Rio Quebra-Perna $\left(25^{\circ} 05^{\prime} 38^{\prime \prime} \mathrm{S}\right.$ e $50^{\circ} 09^{\prime} 30^{\prime \prime}$ ), Bacia do Rio Tibagi, município de Ponta Grossa, Estado do Paraná. Foram estabelecidas três estações de coleta, sendo uma no interior do Buraco do Padre e duas na corredeira ao longo do Rio Quebra-Perna.

A temperatura média do ar variou de $15^{\circ} \mathrm{C}$ (maio, julho, setembro e outubro) a $24,3^{\circ} \mathrm{C}$ (dezembro e janeiro), a temperatura média da água de $15,8^{\circ} \mathrm{C}$ (julho) a $22,3^{\circ} \mathrm{C}$ (dezembro), o teor médio de oxigênio dissolvido de $95,7 \%$ (março) a $100,2 \%$ (agosto), o pH médio de 6,1 (julho) a 7,2 (setembro). Ao longo do período de estudo foram coletados manualmente e com auxílio de peneiras e puçás, 827 exemplares, dos quais 384 machos, 311 fêmeas e 132 juvenis. Os animais foram sexados e medidos in loco. Informações adicionais sobre o local e metodologia de coleta encontram-se em SWIECH-AYOUB \& MASUNARI (2001).

Os exemplares juvenis (sem sexo definido) e adultos foram distribuídos em 14 classes de comprimento da carapaça com intervalo de $2,0 \mathrm{~mm}$ e que correspondem ao tamanho médio dos exemplares em cada classe. Os limites para juvenis 
foram: classe A: $2,5 \leftrightarrow 4,4 \mathrm{~mm}$; e classe $\mathrm{B}: 4,5 \leftrightarrow 6,4 \mathrm{~mm}$ e para adultos, classe C: $6,5 \leftrightarrow 8,4 \mathrm{~mm}$; classe D: $8,5 \leftrightarrow 10,4 \mathrm{~mm}$; classe E: $10,5 \leftrightarrow 12,4 \mathrm{~mm}$; classe F: 12,5 $\leftrightarrow 14,4 \mathrm{~mm}$; classe G: $14,5 \leftrightarrow 16,4 \mathrm{~mm}$; classe $\mathrm{H}: 16,5 \leftrightarrow 18,4 \mathrm{~mm}$; classe I: 18,5 $\leftrightarrow 20,4 \mathrm{~mm}$; classe J: $20,5 \leftrightarrow 22,4 \mathrm{~mm}$; classe $\mathrm{K}: 22,5 \leftrightarrow 24,4 \mathrm{~mm}$; classe L: 24,5 $\leftrightarrow 26,4 \mathrm{~mm}$; classe $\mathrm{M}: 26,5 \leftrightarrow 28,4 \mathrm{~mm}$ e classe $\mathrm{N}: 28,5 \leftrightarrow 30,4 \mathrm{~mm}$.

No estudo de distribuição de frequeência de machos e fêmeas (Fig. 2), os juvenis foram distribuídos aleatoriamente (por sorteio) entre ambos os sexos. Este artifício foi necessário devido à impossibilidade de reconhecer o sexo neste estágio com a metodologia empregada no presente trabalho. Nos demais indivíduos, a sexagem foi feita baseada na presença dos quatro pares de pleópodos no abdome das fêmeas e ausência destes nos machos.

Alguns exemplares adultos, incluindo fêmeas ovígeras foram trazidos ao laboratório e mantidos em aquário até a eclosão dos juvenis. O aquário foi abastecido com a água do local de coleta e mantido oxigenado com aeração constante, em temperatura ambiente. No fundo do aquário foram colocados seixos que serviram de abrigo para os mesmos. Após a liberação dos juvenis dos pleópodos das fêmeas, foi tomada a medida do comprimento da carapaça dos mesmos.

Foi testada a hipótese de nulidade na proporção de sexos mensal e por classes de tamanho, através do teste de qui-quadrado para uma amostra, com um grau de liberdade a 95\% de nível de confiança (SIEGEL 1981). Os juvenis foram excluídos nesta análise.

Para reconhecimento dos estádios de desenvolvimento das fêmeas, foi estipulado chamar de imaturas, aquelas com comprimento da carapaça inferior ao da menor fêmea ovígera registrada no presente estudo $(12,3 \mathrm{~mm}$ de comprimento de carapaça), ou seja, daquela fêmea sexualmente ativa. Fêmeas acima ou igual a esse valor foram consideradas maturas. Estas ainda foram discriminadas em fêmeas ovígeras (com ovos nos pleópodos), fêmeas com juvenis aderidos aos pleópodos e não-ovígeras. Nas fêmeas, o ponto de inflexão do crescimento relativo $(12,7 \mathrm{~mm})$ ficou muito próximo ao observado na menor fêmea ovígera $(12,3 \mathrm{~mm})$. Para reconhecimento dos estádios de desenvolvimento dos machos, foi utilizado o ponto de inflexão do crescimento relativo, o qual apareceu em aproximadamente 17,5 mm de comprimento da carapaça. Machos medindo menos que este valor foram chamados imaturos, e os maiores que $17,5 \mathrm{~mm}$ de comprimento da carapaça, de maturos (SWIECH-AYOUB \& MASI'NARI 2001).

\section{RESULTADOS}

A distribuição de freqüência absoluta de machos e fêmeas $(\mathrm{N}=695)$ de $A$. castro nas classes de comprimento da carapaça, permitiu detectar três grupos etários definidos na população, em ambos os sexos. O primeiro engloba os animais das classes C, D e E (6,5 a 12,4 mm de comprimento da carapaça), o segundo de F, G, H e I ( 12,5 a 20,4 mm) e o terceiro de J, K, L, M e N (20,5 a 30,4 mm). Não houve fêmeas na classe N (Fig. 1). A proporção de sexos ao longo do período amostral foi próxima de 1:1 no primeiro e segundo grupos etários, sem diferença estatisticamente significativa $\left(x^{2}(3,84)=0,07\right.$ e 1,16 respectivamente), enquanto no terceiro grupo etário foi de 1:0,73 (a favor dos machos, $x^{2}=8,95$ ). 

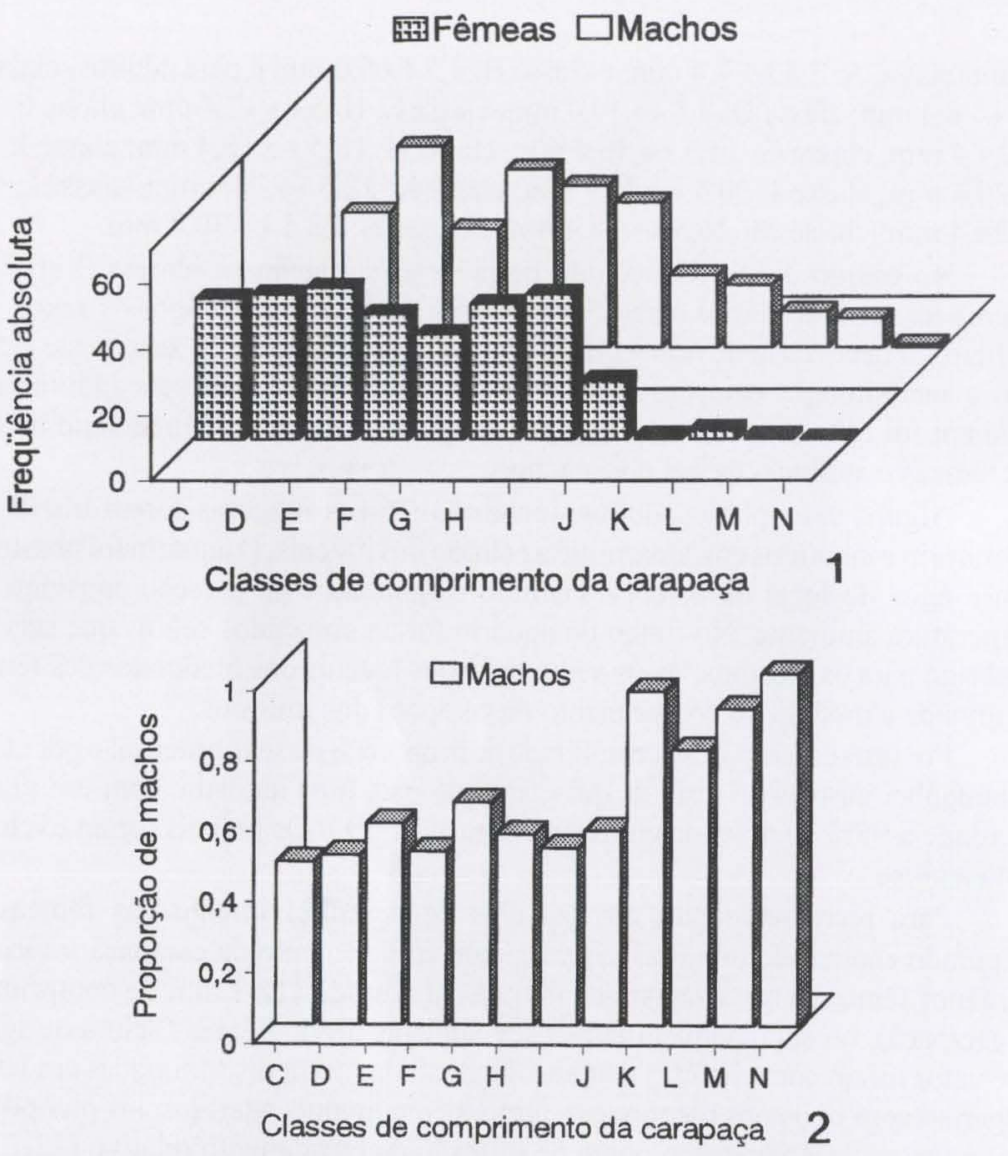

Figs 1-2. Aegla castro. Distribuição da freqüência absoluta de machos e fêmeas adultos (1) e proporção de machos adultos (2) nas classes de comprimento da carapaça. (C) $6,5 \leftrightarrow 8,4$

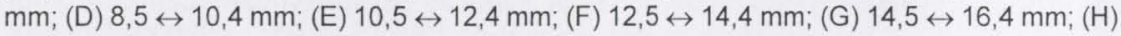
$16,5 \leftrightarrow 18,4 \mathrm{~mm} ;$ (I) $18,5 \leftrightarrow 20,4 \mathrm{~mm} ;$ (J) $20,5 \leftrightarrow 22,4 \mathrm{~mm} ;(\mathrm{K}) 22,5 \leftrightarrow 24,4 \mathrm{~mm}$; (L) $24,5 \leftrightarrow$ $26,4 \mathrm{~mm}$; (M) $26,5 \leftrightarrow 28,4 \mathrm{~mm}$; (N) $28,5 \leftrightarrow 30,4 \mathrm{~mm}$.

A análise da proporção de sexos por classe de comprimento da carapaça revelou que houve uma razão de 1:1 na maioria das classes; somente na classe $\mathrm{K}$ houve forte predominância de machos, com razão de sexos $=19\left(x^{2}(3,84)=8,1\right)$. Em N, houve apenas machos (Fig. 2).

Os juvenis somaram 132 e estiveram distribuídos nas classes A e B (Fig. 3), com predominância nesta última $\left(\mathrm{x}^{2}(3,84)=16,5\right)$. Houve 253 machos imaturos e 131 maturos, distribuídos nas classes $\mathrm{C}$ a $\mathrm{H}$ e de $\mathrm{H}$ a $\mathrm{N}$, respectivamente. $\mathrm{O}$ histograma de distribuição dos machos imaturos foi bimodal e o dos maturos unimodal assimétrico (Fig. 3). As fêmeas imaturas somaram 121 com distribuição unimodal, enquanto que as maturas e ovígeras somaram 177 e 13 , respectivamente, e os histogramas de distribuição foram trimodal e bimodal (Fig. 3). 


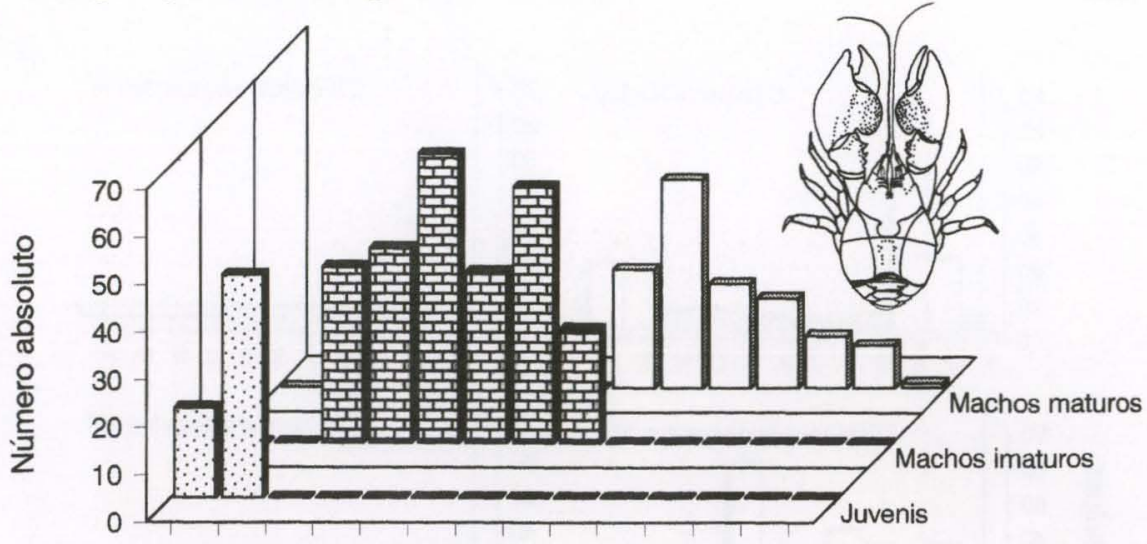

A B C D D E F G H I J $\mathrm{K}$ L $M$ M

Classes de comprimento da carapaça

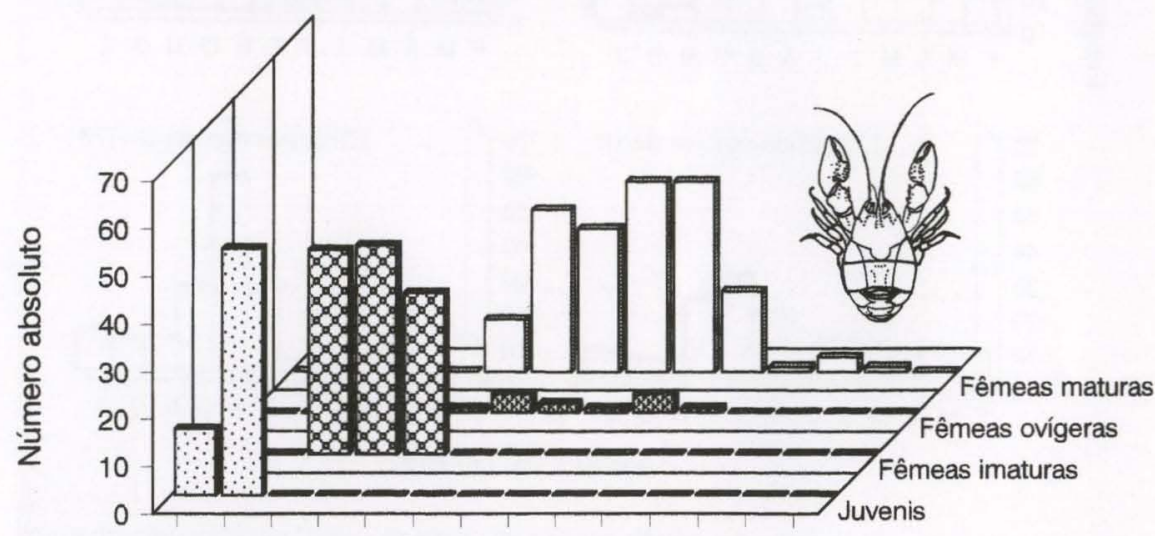

A B C D E F G H I J K L M N

Classes de comprimento da carapaça

Fig. 3. Aegla castro. Distribuição dos diversos estágios de desenvolvimento de ambos os sexos nas classes de comprimento da carapaça. (A) 2,5 $\leftrightarrow 4,4 \mathrm{~mm}$, (B) $4,5 \leftrightarrow 6,4 \mathrm{~mm}$ (para demais classes, ver legenda da figura 1).

A figura 4 apresenta a flutuação anual da freqüência absoluta dos vários estádios de desenvolvimento reconhecidos em A. castro, para ambos os sexos. O estágio juvenil apresentou um pico em abril com um decréscimo brusco nos meses seguintes e faltou em maio e setembro; voltou a aumentar a partir de outubro e formou uma tendência a um segundo pico em janeiro. O número de juvenis variou de um (fevereiro, junho, julho) a 64 (abril).

Machos imaturos ocorreram em todos os meses de coleta, variando de 1 indivíduo (dezembro) a 57 (setembro). O histograma de freqüência mostrou picos em março, julho, setembro e janeiro. Os machos maturos, também, ocorreram durante todo o período amostral com uma amplitude de variação de 1 (julho) a 29 (setembro). Houve um pico em setembro e queda significativa de novembro a fevereiro (Fig. 4). 

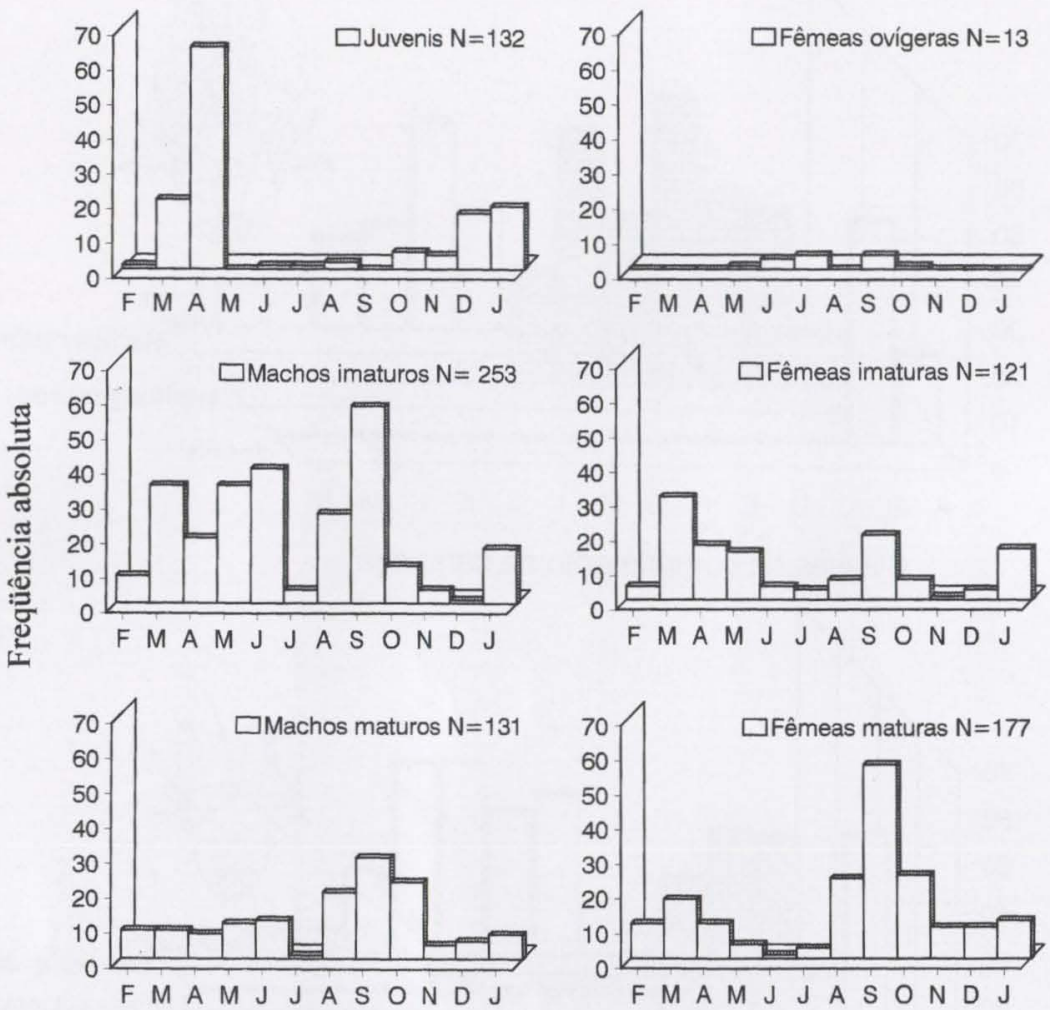

\section{Meses de coleta}

Fig. 4. Aegla castro. Flutuação anual da freqüência absoluta de juvenis e caranguejos maturos e imaturos de ambos os sexos, no período estudado.

Dentre as fêmeas imaturas, houve três picos na freqüência absoluta que coincidiram com os picos dos machos imaturos. A amplitude de variação foi de um (novembro) a 30 (março) exemplares. As fêmeas maturas não-ovígeras ocorreram durante todo o ano apresentando um pico em setembro, e uma queda brusca na abundância de fêmeas maturas de novembro a janeiro; esta flutuação na abundância coincidiu com a dos machos maturos (Fig. 4). A amplitude de variação foi de um (junho) a 56 (setembro) espécimes.

As fêmeas ovígeras foram registradas somente de maio a outubro (exceção de agosto) (Fig. 4), o que corresponde ao período reprodutivo da espécie. A freqüência flutuou de um (maio e outubro) a quatro (julho e setembro). A fêmea capturada em outubro apresentou juvenis recém-eclodidos aderidos aos pleópodos.

A proporção de sexos da totalidade da população de $A$. castro mostrou uma razão sexual média próxima de $1: 1\left(x^{2}(3,84)=3,83\right)$. Os machos predominaram significativamente somente em maio e junho com freqüência relativa de 0,70 $\left(x^{2}(3,84)=4,96\right)$ e $0,86\left(x^{2}(3,84)=15,21\right)$ respectivamente. Em julho e dezembro, 
a proporção de machos foi numericamente mínima, porém, estatisticamente não-significativa $\left(x^{2}(3,84)=0,83\right.$ e 1,0 respectivamente).

Das treze fêmeas ovígeras de $A$. castro capturadas, cinco foram obtidas na estação I e oito nas II e III. Um estudo da distribuição dos comprimentos médio, máximo e mínimo da carapaça $(\mathrm{mm})$ destas fêmeas mostrou dois grupos distintos: o primeiro com valor médio variando de 17,5 a $19,3 \mathrm{~mm}$ e ocorrentes de maio a julho, e o segundo de 13,7 a 15,4 mm de setembro a outubro (Fig. 5). Esta queda no comprimento médio da carapaça no segundo grupo pode ser indício do recrutamento de um novo grupo etário de fêmeas para a população sexualmente ativa. Enquanto em maio e junho houve exclusivamente fêmeas ovígeras de maior porte, em julho, surgem fềmeas ovígeras menores, acentuando-se mais em setembro. Em outubro, as fêmeas eram de tamanho intermediário.

Em junho e julho, a proporção de ovígeras foi maior que nos demais meses: $38 \%$ das fềmeas estavam ovígeras em junho e $40 \%$ em julho (Fig. 6). Junho também foi o mês em que o comprimento médio da carapaça de fềmeas ovígeras foi maior (Fig. 5). Nos meses seguintes a julho observou-se um decréscimo acentuado na proporção relativa destas.

Os ovos de A. castro apresentaram coloração que variou de laranja até marrom. Quanto mais adiantado é o estágio de desenvolvimento embrionário, mais escura é a cor do ovo. Em aquário, os recém-eclodidos permaneceram presos aos pleópodos das fềmeas por aproximadamente 15 dias e, com cerca de 2,2 $\mathrm{mm}$ de comprimento da carapaça, os juvenis abandonaram os pleópodos da fêmea-mãe, indicando emancipação dos mesmos. Após duas semanas, os juvenis desapareceram por completo do aquário, sem deixar vestígios, provavelmente vítimas de canibalismo por parte das fêmeas adultas, a exemplo do constatado por RoDRIGUES \& HEBLING (1978). Durante o período de incubação, as fêmeas não se alimentaram e mantiveram-se no fundo do aquário, com o abdome mergulhado na camada de pedregulhos. Os demais adultos aceitaram como alimento, artêmias frescas, pedaços de peixes e náiades frescas. Os juvenis aceitaram náuplius de artêmia.

Os menores juvenis Aegla castro registrados em campo foram obtidas em outubro, os quais estavam ainda aderidos aos pleópodos de uma fêmea. Os juvenis estiveram presentes durante todo o período amostral, com exceção de maio e setembro (Fig. 7). Ocorreram dois picos de recrutamento, o primeiro, mais intenso, em abril quando os juvenis perfizeram $55 \%$ da população total, e o segundo em dezembro (47\%). Durante o período reprodutivo da espécie (maio a outubro), eles foram pouco numerosos. O menor juvenil registrado em campo ocorreu em abril e mediu 3,1 mm de comprimento da carapaça.

\section{DISCUSSÃO}

Os três grupos etários observados para A. castro, no presente estudo, representam três coortes (Fig. 1). Considerando-se que há dois pulsos de recrutamento no ano, portanto duas coortes, uma a cada 5-6 meses aproximadamente, há hipoteticamente, um ano e meio de intervalo entre os componentes da coorte mais nova e a da mais velha. Considerando o tempo de incubação, que é de aproximadamente 5-6 meses, é provável que a longevidade da espécie não deva ultrapassar os dois 

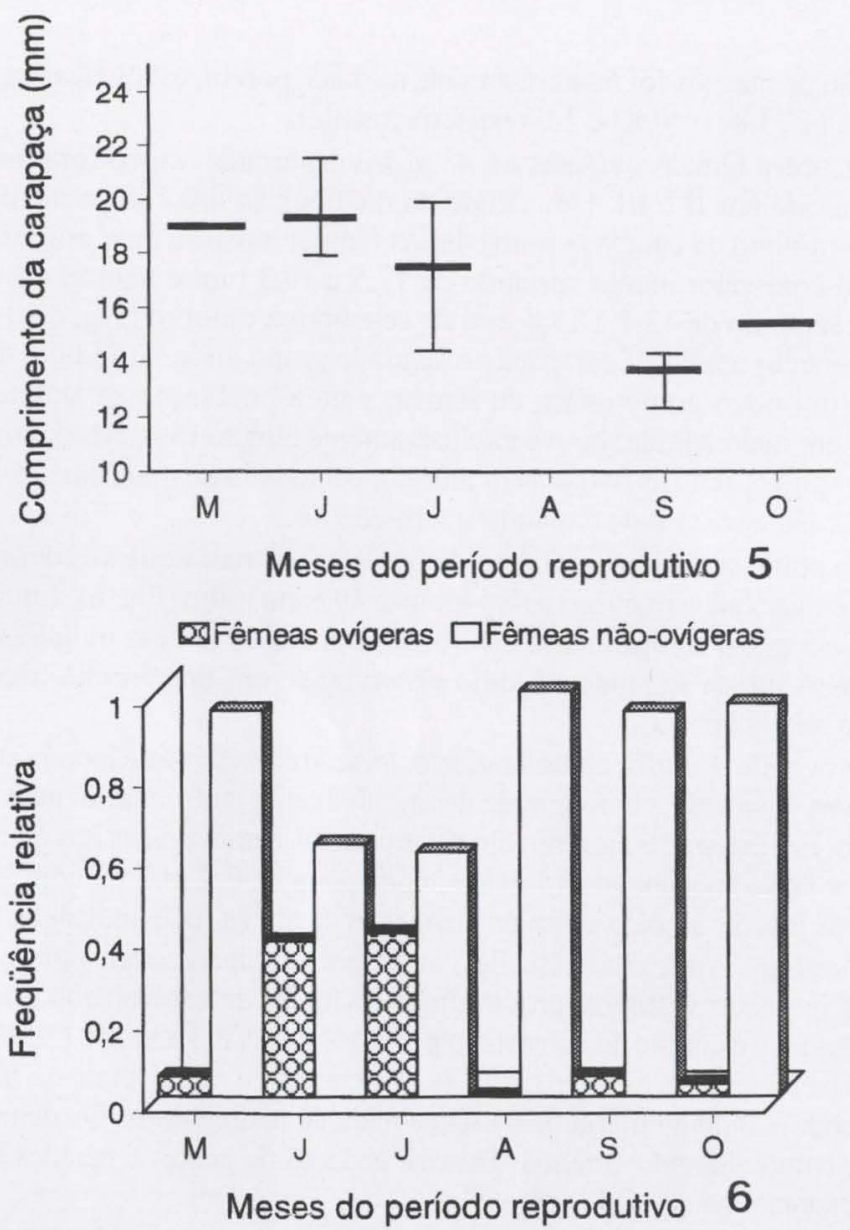

Figs 5-6. Aegla castro. (5) Comprimentos médio, máximo e mínimo da carapaça $(\mathrm{mm})$ das fêmeas ovígeras obtidas durante o periodo reprodutivo; (6) distribuição de freqüência relativa de fêmeas ovigeras e não ovígeras obtidas no período reprodutivo.

anos, com duas coortes anuais. A longevidade estimada pelo método de Petersen para A. laevis laevis (BAHAMONDE \& LÓPEZ 1961) foi de aproximadamente 37 meses, valor cerca de $35 \%$ maior do que em A. castro. Para A. platensis BUENo \& BOND-BUCKUP (2000) estimaram a longevidade em dois ano e meio.

Dentro dos quatro modelos de proporção de sexos propostos por WENNER (1972) para crustáceos marinhos, A. castro se enquadra no modelo padrão, que condiz com a proporção mendeliana, já que machos e fềmeas são igualmente representados na maioria das classes de tamanho.

Considerando-se a população total ao longo do período amostral, a predominância de machos, com diferenças significativas somente em maio e junho poderia levar à aceitação da hipótese da igualdade na proporção de sexos. Este 


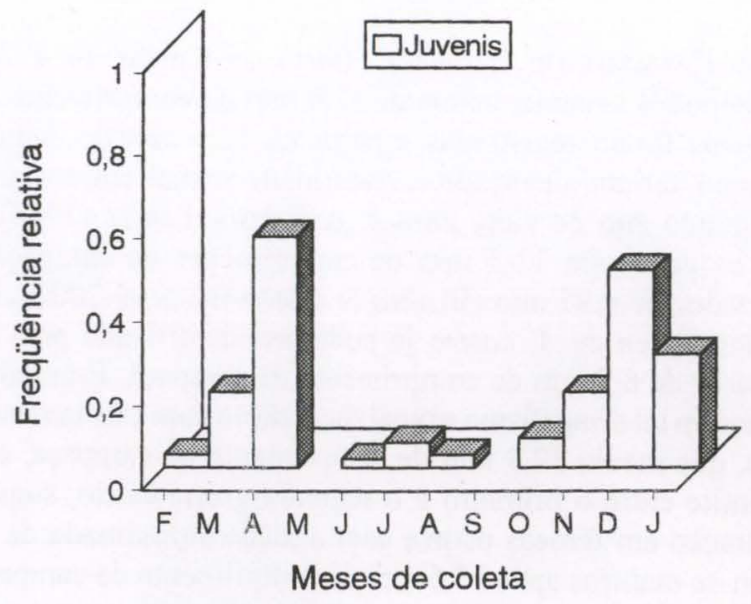

Fig. 7. Aegla castro. Freqüência relativa de juvenis nos meses de amostragem.

fato foi observado, também, em populações de A. platensis no Arroio do Mineiro, Rio Grande do Sul (BUENO \& BOND-BuCKUP 2000). Esta proporção pode ser explicada pela citação de MARGALEF (1977) que estabelece que, em populações cujos animais vivem dispersos em um meio e os encontros entre os sexos ocorrem ao acaso, a razão de sexos mais favorável é a de 1:1. Esta razão é ainda observada na maioria das classes de tamanho no presente estudo.

A predominância de machos na classe K pode ser resultado de comportamento diferencial, já que durante o pico do período reprodutivo (quando os machos predominaram em maio e junho) as fêmeas poderiam ter emigrado ou estar escondidas nos níveis inferiores da camada de pedregulhos. A favor desta última hipótese, foi observado em aquário que, durante o período de incubação dos ovos, as fêmeas ovígeras não se alimentaram e passaram a maior parte do tempo enterradas de modo críptico nos pedregulhos.

Outra hipótese está fundamentada na possível taxa de mortalidade maior dentre as fêmeas maturas causada pela predação: a massa de ovos as torna mais pesadas e lentas para a fuga, ou o estresse sofrido pelas mesmas após o período reprodutivo as torna mais vulneráveis. Esta inferência está baseada na observação de BAHAMONDE \& LÓPEZ (1961) com A. laevis laevis, cuja taxa de mortalidade é maior dentre as fêmeas na época da postura, de modo especial, após a segunda postura.

O predomínio numérico de machos sobre fêmeas também foi constatado para A. perobae, A. paulensis e A. platensis (RODRIGUES \& HEBLING 1978; LÓPEZ 1965; BUENO \& BOND-BUCKUP 2000), ocorrendo o inverso para A. laevis laevis, onde os autores relacionaram o fato com o período de desova e liberação de juvenis (BAHAMONDE \& LÓPEz 1961). Deve-se considerar que as condições ambientais às quais estão sujeitas as populações podem influenciar de maneira diversa na taxa de sobrevivência e na proporção de sexos das mesmas (MARGALEF 1977). 
Segundo BAHAMONDE \& LóPEz (1961), as fêmeas de A. laevis laevis apresentam pleópodos somente acima de $12,0 \mathrm{~mm}$ de comprimento de carapaça e fêmeas ovígeras foram registradas a partir de $12,5 \mathrm{~mm}$ de comprimento de carapaça, as quais teriam alcançado a maturidade sexual entre o nono mês e o começo do segundo ano de vida. Para A. paulensis, LóPEZ (1965) registrou a menor fêmea ovígera com $11,5 \mathrm{~mm}$ de comprimento da carapaça, e para $A$. platensis, um valor de $9,87 \mathrm{~mm}$ (BUENO \& BOND-BUCKUP 2000). No presente estudo, a menor fêmea de $A$. castro já pode ser identificada pela presença de pleópodos a partir de $6,5 \mathrm{~mm}$ de comprimento de carapaça. Entretanto pouquíssimas apresentaram tal dimorfismo sexual secundário com este tamanho. A menor fêmea ovígera, que mediu $12,3 \mathrm{~mm}$ de comprimento de carapaça, está próxima ao tamanho-limite entre o primeiro e o segundo grupo etário, sugerindo que a primeira maturação em fêmeas ocorra com a idade aproximada de um ano. Os machos tornam-se maturos após 17,5 mm de comprimento de carapaça, demonstrado pela análise do crescimento relativo. Como eles atingem um tamanho total superior aos das fêmeas, maturam com cerca de $5 \mathrm{~mm}$ a mais que as fêmeas. Estas diferenças no tamanho da menor fêmea ovígera, certamente, estão relacionadas com o tamanho máximo atingido pelas respectivas espécies.

A reprodução periódica ou mais intensa num certo periodo do ano parecem caracterizar as espécies de Aegla que tiveram sua biologia estudada. O período reprodutivo da maioria das espécies deste gênero coincide com os meses mais frios, ou seja, entre outono e primavera. Para A. laevis laevis o período se estende desde o final de março até outubro e para A. paulensis de junho a outubro, com possibilidade de ter iniciado antes. O período reprodutivo de $A$. perobae compreendeu desde a metade de abril até a metade de outubro (BAHAMONDE \& LÓPEZ 1961; RODRIGUES \& HEBLING 1978; LÓPEZ 1965). Embora a reprodução de A. platensis estenda-se por todo o ano, o mês de julho (inverno) foi o de maior atividade reprodutiva (BUENO \& BOND-BUCKUP 2000). Aegla castro não fugiu à regra, pois, o seu período reprodutivo vai de maio a outubro. Observa-se uma forte correlação entre reprodução e temperatura, porém o foto-período pode ser um forte indutor da reprodução nestes animais, como observou LitTLE (1968) para Palaemonetes pugio Holthuis, 1949.

Segundo BAHAMONDE \& LÓPEZ (1961), o início da desova pode apresentar variações de algumas semanas de um ano para outro, talvez devido a fatores ambientais. Isto influencia a mortalidade dos juvenis, porque o desenvolvimento dos mesmos nos meses que sucedem à postura é uma função direta das referidas condições ambientais.

De modo geral, o período reprodutivo da maioria das espécies cuja biologia é conhecida dura cerca de seis meses, como foi verificado para $A$. castro no presente trabalho. A. platensis constitui uma exceção (BUENO \& BOND-BUCKUP 2000). Os juvenis registrados ao longo de praticamente todo o período amostral são decorrentes das diferentes taxas de crescimento entre grupos de juvenis produzidos ao longo do extenso período reprodutivo (maio a outubro). Assim, a reprodução de $A$. castro caracteriza-se como tipo descontínuo ou periódico. No presente trabalho, os juvenis de $A$. castro começaram a eclodir em outubro, como em $A$. perobae, e permaneceram aderidos aos pleópodos das fềmeas por cerca de 8 a 12 dias. Esta coincidência na 
data de eclosão pode ser estar relacionada com as condições climáticas semelhantes entre os dois locais: interior do Estado de São Paulo e o Segundo Planalto do Estado do Paraná. Em A. laevis laevis, os juvenis eclodidos em agosto e com 1,2 mm de comprimento da carapaça estavam aderidos aos pleópodos das fêmeas.

A baixa freqüência de fêmeas ovígeras ou com juvenis presos aos pleópodos durante o período de estudo, pode estar relacionado com estratégias de reprodução ou comportamento destas fêmeas. Na tentativa de buscar hábitats mais abrigados, esta parcela da população pode ter sido subestimada.

A presença de dois grupos etários sexualmente ativos observados no presente estudo corrobora a descrição de BAHAMONDE \& LÓPEZ (1961) e de BUENO \& BOND-BUCKUP (2000), que verificaram em A. laevis laevis e A. platensis, respectivamente, a participação de fêmeas no processo reprodutivo da espécie por dois anos sucessivos. O primeiro pulso de fêmeas ovígeras (maio, junho e julho) foi constituído pelas mais velhas (multíparas), enquanto que o segundo pulso (setembro e outubro) por fêmeas que entraram em atividade reprodutiva pela primeira vez (primíparas). Esses dois pulsos consistem numa estratégia adaptativa que favorece o êxito da reprodução anual, uma vez que, permite um espaço de tempo de cerca de 5-6 meses na a liberação das duas coortes do ano. Com isso, se alguma modificação drástica ocorrer no ambiente, uma nova liberação de juvenis permitirá a sobrevivência da espécie no local. Portanto, os juvenis recrutados em abril foram liberados pelas fêmeas primíparas fecundadas no final do período reprodutivo, enquanto que os recrutados em dezembro, provavelmente foram liberados pelas fêmeas multíparas fecundadas no início do período reprodutivo da espécie. A partir disso, pode-se inferir que, durante o período de cinco meses, ovos (mais tempo) e juvenis (menos tempo) se mantém aderidos aos pleópodos das fêmeas, como observado por BAHAMONDE \& LOPEZ (1961) para A. laevis laevis.

O pico de recrutamento de A. paulensis (LóPEZ 1965) ocorreu em setembro, o que não se verifica em $A$. castro, cujos juvenis estiveram presentes durante todo o período amostral com exceção justamente no mês de setembro. Para $A$. laevis laevis, o pico de recrutamento ocorreu de novembro a fevereiro (BAHAMONDE \& LOPES 1961), coincidindo com um dos picos de A. castro (dezembro). No caso de $A$. platensis, o pico de recrutamento ocorreu em agosto, um mês após a ocorrência do maior número de fêmeas ovígeras registradas no ano (BUENO \& BOND-BUCKUP 2000).

De modo geral, os juvenis foram recrutados nos meses em que a temperatura da água tende a aumentar (fim do inverno e começo da primavera), o que deve favorecer o desenvolvimento dos mesmos.

AGRADECIMENTOS. À CAPES, na pessoa de seu Presidente, pela Bolsa de Mestrado concedida a B.P. Swiech-Ayoub. Ao Sr. Ferdinando Schaeffer, pela permissão do acesso à sua propriedade para execução do presente projeto. Ao Prof. Dr. Paulo Pezzuto da Universidade do Vale do Itajai e ao Prof. Dr. José Marcelo Aranha da Universidade Federal do Paraná, pela leitura crítica do trabalho. Às colegas de trabalho Cláudia, Edinalva e Bárbara, pelo precioso auxílio nos trabalhos de campo. 


\section{REFERÊNCIAS BIBLIOGRÁFICAS}

Bahamonde, N.N. \& M.T. López. 1961. Estudios biológicos en la problación de Aegla laevis laevis (Latreille) de el Monte (Crustacea, Decapoda, Anomura). Invest. Zool. Chil., Santiago, 7: 19-58.

Bueno, A.A.P. \& G. Bond-Buckup. 2000. Dinâmica populacional de Aegla platensis Schmitt (Crustacea, Decapoda, Aeglidae). Revta bras. Zool. 17 (1): 43-49.

Bueno, A.A.P.; G. Bond-Buckup \& L. Buckup. 2000. Crescimento de Aegla platensis Schmitt em ambiente natural (Crustacea, Decapoda, Aeglidae). Revta bras. Zool. 17 (1): 51-60.

JARA, C.G.; M. CERDA \& A. PAlmA. 1995. Geographic range of Aegla papudo Schmitt, 1942 (Crustacea: Decapoda: Anomura: Aeglidae), and conservational status of its populations. Gayana, Zool., 59 (1): $13-22$

LitTLE, G. 1968. Induced winter breeding and larval development in the shrimp, Palaemonetes pugio Holthuis (Caridea, Palaemonidae). Crustaceana, Leiden, 2: 19-26.

López, M.T. 1965. Estudios biológicos en Aegla odebrechtii paulensis, Schmitt. Bol. Fac. Filos. Ciênc. Univ. São Paulo 25: 301-314

MARGALEF, R. 1977. Ecologia. Barcelona. Ediciones Omega. 951 p.

Mouchet, S. 1932. Notes sur la biologie du galathéide Aeglea laevis (Latr.). Bull. Soc. Zool. Fr., Paris, 57 (59): 316-340.

Rodrigues, W. \& N. Hebl.ING. 1978. Estudos biológicos em Aegla perobae Hebling \& Rodrigues, 1977 (Decapoda, Anomura). Rev. Brasil. Biol. 38 (2): 383-390.

SASTRY, A.N. 1983. Ecological aspects of reproduction, p. 179-270. In: F.J. VERnBerg \& W.B. Vernberg (Eds). Environmental adaptations. The biology of Crustacea. New York, New York Academic, Vol. 8, XXVI+383p.

SIEGEL, S. 1981. Estatística não paramétrica para as ciências do comportamento. São Paulo, Ed. McGraw-Hill, 350p.

SWIECH-AYOUB, B.P. \& S. MASUNARI. 2001. Flutuação temporal e espacial de abundância e composição de comprimento da carapaça de Aegla castro Schmitt, 1942 (Crustacea, Anomura, Aeglidae) no Buraco do Padre, Ponta Grossa, Paraná, Brasil. Revta bras. Zool. 18 (3): 1003-1017.

WENNER, A.M. 1972. Sex ratio as a function of size in marine Crustacea. Amer. natur. 106 (949): 321-350.

Recebido em 28.XII.2000; aceito em 28.VIII.2001 